\title{
Letramento Infantil na Biblioteca Escolar: desenvolvendo habilidades básicas para futuros leitores competentes
}

\author{
Early Literacy at Library Schools: basic skills development for future successful readers
}

\begin{abstract}
Nádia Maria dos Santos Hommerding
Doutora em Ciência da Informação pela Escola de Comunicação e Artes da Universidade de São Paulo -

ECA/USP.

Docente do Programa de Pós-graduação da Fundação Escola de Sociologia e Política de São Paulo - FESPSP,

(Núcleo de Ciência da Informação)

E-mail: hommerding@gmail.com
\end{abstract}

\begin{abstract}
Resumo
Este artigo busca relatar parte da experiência e aprendizado da autora atuando como bibliotecária no ${ }^{1}$ Sistema de Biblioteca Publicas de Miami Dade (MDPLS) em Miami, Estados Unidos. Apresenta o conceito de Letramento Infantil (Early Literacy) e as seis competências básicas para seu desenvolvimento em bebês e crianças de zero mês a seis anos de idade em relação aos hábitos de leitura e interação com os livros e biblioteca. Aponta para o importante e estratégico papel da biblioteca escolar e da integração de práticas profissionais entre bibliotecários e professores escolares quanto ao desenvolvimento de habilidades de leitura e escrita, considerando os conceitos de letramento e alfabetização, em leitores na primeira infância. Reconhece na biblioteca escolar, importante aliada no processo de criação e apropriação de hábitos de leitura, além do desenvolvimento de opinião crítica nos pequenos cidadãos, quando apropriadamente incluída nos projetos pedagógicos da instituição de ensino.
\end{abstract}

Palavras-chave: Letramento. Alfabetização. Primeira infância. Professores. Bibliotecários. Letramento infantil. Early literacy. Biblioteca escolar. Bebês. Crianças.

\begin{abstract}
The current paper intends to report some of the experience and learning acquired by the author working as a Librarian at Miami Dade Public Library Systems (MDPLS) in the United States of America. Introduces the concept of Early Literacy and the six basic skills for developing in babies and children ( 0 months to 5 years old) abilities for reading and writing. Points out the strategic and important role of school library, librarians, school professors, teachers, educators regarding the development of early literacy Acknowledge the school libraries as suitable and strategic allied in the process of development and acquiring reading and writing skills for long life learning. It Advocates for the positive aspects and impact for developing young critical freethinkers. It emphasizes the importance of the alignment between the mission and goals of the school library in accordance with the pedagogical and methodological goals of the educational institution.
\end{abstract}

Keywords: Literacy. Early literacy. School library. Schools. Babies. Children. Reading skills. Writing. Teachers. Librarians

1 www.mdpls.org

Bibl. Esc. em R., Ribeirão Preto, v. 4, n. 2, p. 33-52, 2016.

DOI: 10.11606/issn.2238-5894.berev.2016.111294 


\section{Introdução}

É grande o desafio de traduzir o termo early literacy para a língua portuguesa. Não se trata apenas de uma mera tradução, mas, sim, de uma compreensão abrangente do conceito por si, e qualquer tentativa de transposição do termo do inglês para o português é discutível. Após muita consideração e troca de ideias e opiniões com profissionais tanto da área de Educação quanto Informação, decidimos pelo termo letramento infantil, ao invés de letramento precoce ou letramento prematuro/inicial, que pode trazer compreensões distintas e distantes do que de fato, se trata este conceito e ação.

De acordo com Kishimoto (2010), no Brasil, a tradução de literacy por letramento é atribuída a Mary Kato, em 1986, sendo que o termo tem sido usado de maneira abrangente nas discussões e na literatura dos educadores brasileiros. Em Portugal, por outro lado, usa-se o termo literacia precoce ou emergente, enquanto que os países latino-americanos, de língua espanhola optam por alfabetización temprana.

É importante salientar que este artigo reflete muito da observação da autora e experiência profissional durante os dois anos de trabalho de campo no Sistema de Bibliotecas Públicas de Miami Dade - Miami Dade Public Library System (MDPLS), no condado de Miami, Estados Unidos. Tendo iniciado a carreira naquele país como Librarian I, foi posteriormente promovida ao cargo de Librarian II. De acordo com o plano de carreira daquele Sistema de Bibliotecas, nesta posição os bibliotecários são responsáveis pelo planejamento e implantação dos programas voltados aos bebês, crianças e adolescentes. Trata-se de uma posição estratégica de vice-gerência e gerência, no plano de carreira daquele Sistema de Bibliotecas.

Por ocasião de seu retorno, para restabelecer residência no Brasil, a autora, passou a atuar na área acadêmica, de ensino e pesquisa. Como professora de cursos de pós-graduação e extensão em instituições de ensino na área de Biblioteconomia e Ciência da Informação, buscou trazer contribuições de seu aprendizado teórico e prático no exterior, no intuito de contribuir para a reflexão de profissionais, estudantes, pesquisadores e instituições nacionais sobre a oportunidade de desenvolvimento e aplicação de práticas de Letramento Infantil que estão acontecendo em nível global, na atual sociedade da informação e do conhecimento.

Este artigo busca mostrar aos gestores de informação das bibliotecas e escolares e públicas, a importância de assumir e gerir esse papel sócio-educacional em espaços 
apropriados e destinados ao público infantil, bem como apresentar as experiências do Sistema de Bibliotecas Públicas de Miami, de forma a possibilitar uma reflexão sobre as possibilidades de aplicação de modelo semelhante no ambiente brasileiro, evidentemente, adequando-o ao contexto socioeconômico e cultural.

\section{O modelo norte-americano}

O Instituto Nacional de Desenvolvimento e Saúde da Criança (National Institute of Child Health and Human Development - NICHD) dos Estados Unidos define Early Literacy, ou Letramento Infantil, como "o que as crianças sabem sobre ler e escrever antes que elas possam de fato ler e escrever por conta própria". Inúmeros estudos têm demonstrado que crianças consistentemente expostas a uma variedade de histórias e experiências tornam-se melhores leitores, ouvintes, expandem seus vocabulários e desenvolvem maior capacidade de compreensão de textos, além de melhor habilidade para verbalização de pensamentos e opiniões do que aquelas que não foram expostas a tais experiências (PAYNE; WHITEHURST; ANGELL, 1994; DUKE; MOSES, 2003).

Com esse espírito, a iniciativa "Toda Criança Pronta para Ler na Sua Biblioteca" (Every Child Ready to Read @ your Library) foi desenvolvida nos Estados Unidos. Tratou-se de iniciativa da Associação de Bibliotecas Públicas (Public Library Association - PLA) e da Associação de Serviços de Bibliotecas para Crianças, esta última uma divisão da Associação Americana de Bibliotecas (Association for Library Service to Children of the American Library Association - ALA). Naquele país, a biblioteca pública tem papel fundamental na formação de seu público infantojuvenil sendo parceira das escolas públicas ou privadas no desenvolvimento de certas aptidões, por meio da hora do conto, oficinas, seminários, palestras com especialistas no tema, e também pelo uso de livros e demais recursos e programas disponíveis na biblioteca.

Um dos aspectos da iniciativa foi a criação de documentos, roteiros, guias e disponibilização de bibliografia especializada e direcionada, oferecendo materias de suporte e didáticos para a elaboração de seminários e oficinas. Essas atividades são realizadas nas bibliotecas públicas e escolares por bibliotecários e profissionais da área de educação, leitura, artes, e early literacy (letramento infantil). Elas visam, basicamente, à orientação de professores, pais, cuidadores e tutores de bebês e crianças até seis anos de idade, 
particularmente, em relação às técnicas e práticas do letramento infantil. Estes materiais fundamentais foram desenvolvidos por pesquisadores, educadores e bibliotecários financiados pelo NICHD (GOTHING; MARTIN-DIAZ, 2008).

O Projeto Early Literacy da Associação de Bibliotecas Públicas (ALP) começou no ano de 2000, em parceria com o NICHD, que lançou naquela ocasião, um relatório baseado numa pesquisa nacional relacionada ao desenvolvimento da criança e da leitura. Tal pesquisa, denominada "Ensinando crianças a ler: avaliação baseada em evidência da pesquisa de literatura científica em leitura e suas implicações para a instrução na leitura" apresentou informações essenciais aos pais, tutores de crianças e bibliotecários sobre a necessidade de estabelecimento de ações e programas voltados a bebês e crianças de zero a cinco anos de idade em relação ao seu desenvolvimento na leitura. O primeiro passo dessa parceria foi a disseminação nacional das informações contidas nesse relatório, por meio das bibliotecas públicas.

Ainda por conta dos resultados desse estudo, foi desenvolvido e estabelecido um programa/modelo para as bibliotecas públicas norte-americanas, voltado aos pais e crianças, no âmbito do letramento infantil. Naquele país, por questões culturais, de tradição, de política pública e de apoio do cidadão, as bibliotecas públicas atingem significativa porcentagem de pais, professores e tutores e as próprias crianças, assegurando impacto nas experiências iniciais do letramento e leitura em idade pré-escolar.

O programa/modelo, desenvolvido por Grover C. Whitehurst e Christopher Lonigan, pesquisadores reconhecidos da área de letramento infantil, era voltado para os pais e tutores de crianças. O principal objetivo dos materiais produzidos a partir do programa foi o de

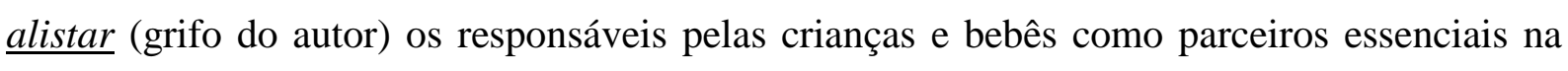
preparação de suas crianças no aprendizado da leitura e prover os métodos mais efetivos para atingir este propósito. (MEYERS; HENDERSON, 2004).

Whitehurts e Lonigan (2001) criaram uma estrutura única para as distintas fases de desenvolvimento de uma criança em relação ao letramento infantil, denominadas:

- Pré-falantes - pre-talkers (0-18 meses), também denominados no jargão das bibliotecas dos Estados Unidos como infants;

- Falantes (talkers) (18 meses aos quatro anos de idade), também chamados toddlers e; 
- Pré-leitores (pre-readers) (quatro a cinco anos de idade), também denominados children.

A partir dessa estrutura, a Associação Americana de Bibliotecas criou o Programa “Toda Criança Pronta para Ler na sua Biblioteca" (Every Child Ready to Read @ Your Library), já mencionado, cujos principais objetivos são:

- Auxiliar as bibliotecas a orientarem os pais e tutores das crianças sobre a importância do Letramento Infantil e seus impactos;

- Disseminar as habilidades ou aptidões essenciais necessárias para o efetivo aprendizado e letramento das crianças antes dos seis anos de idade;

- Ensinar e orientar efetivamente pais e tutores no desenvolvimento destas seis habilidades em suas crianças por meio de recursos didáticos impressos, visuais, etc. disponíveis nas bibliotecas.

Vários Sistemas de Bibliotecas Públicas, de diferentes estados e municipalidades dos Estados Unidos adotaram e passaram a desenvolver as práticas e atividades de Letramento Infantil, oferecendo-as a suas comunidades de usuários. O Miami Dade Public Library System (MDPLS) é um deles, tendo investido muito no Programa.

\section{A experiência de early literacy do Sistema de Bibliotecas Públicas de Miami (MDPLS)}

O programa Prontos para Ler (Reading Ready Early Literacy Program) do MDPLS foi iniciado no ano de 2008 e tem como público-alvo os pais, babás, tios, cuidadores, enfim os tutores, além das próprias crianças, desde seu nascimento até os cinco anos de idade. Para tanto as bibliotecas do Sistema oferecem um ambiente apropriado e recursos técnicos e humanos para o desenvolvimento do letramento (READING, 2009).

O pontapé inicial do programa foi uma campanha para qualificação dos profissionais atuantes na biblioteca por meio de cursos e oficinas, com especialistas no tema dos Estados Unidos, Canadá, entre outros países. Foram confeccionados materiais impressos com textos simples e compactos, com mensagens cuidadosamente escolhidas para garantir impacto no lançamento, bem como chamar a atenção dos usuários reais e potenciais das bibliotecas para o Programa Reading Ready (Pronto para ler). 
Letramento Infantil na Biblioteca Escolar: desenvolvendo habilidades básicas para futuros leitores competentes

Outros tipos de materiais utilizados foram: pôsteres, recursos audiovisuais, computadores e jogos, acessórios, livros de vários tamanhos e estilos (texturizados, minilivros, livros gigantes, com música e sons, poesias, rimas, pop-ups), recursos de dança e da música (instrumentos, CDs e canto). Animais de pelúcia de vários tamanhos e texturas, mobiliário apropriado, cartas de memorização, brincadeiras diversas, tecidos e lenços, tapetes, roupas, sapatos, meias, brinquedos e recursos lúdicos de facial aceitação e apreciados pelos bebês e crianças, fazem parte do acervo e recursos adquiridos e adaptados às atividades de early literacy.

O MDPLS investiu largamente na capacitação técnica de seus funcionários. Desde os diretores, passando por gerentes, assistentes de gerentes, bibliotecários chefes, auxiliares, para profissionais, voluntários, estagiários e guardadores de livros do Sistema, todo o staff, sem exceção, recebeu em algum momento treinamento ou orientação sobre o propósito, abrangência e resultados esperados. $\mathrm{O}$ intuito era o de garantir que todos os participantes do Sistema estivessem preparados para dar informações básicas sobre o Programa.

Segundo especialistas da área, o letramento infantil, como adotado no Sistema de Bibliotecas Públicas de Miami, tem efeito direto no sucesso da criança na escola e além dela; o processo colabora para que as crianças se tornem leitores bem-sucedidos e depende de uma variedade de habilidades ou aptidões específicas a serem desenvolvidas na criança, as quais se tornarão os blocos de construção na aprendizagem da leitura e escrita (DUKE, MOSES, 2003). As seis habilidades ou aptidões do letramento infantil são:

1 - VOCABULÁRIO (Vocabulary) - Saber o nome das coisas é uma habilidade ou competência extremamente importante para as crianças quando estão no processo de aprendizado da leitura. Nos Estados Unidos, pesquisas demonstram que a maioria das crianças entra na escola sabendo entre três a cinco mil palavras, média de palavras conhecidas por crianças até seis anos de idade, cujos pais não têm formação universitária, hábitos de leitura ou de frequentar as bibliotecas públicas. Crianças provenientes de famílias cujos pais têm formação universitária, hábitos de leitura e uso da biblioteca chegam a possuir vocabulário de até vinte mil palavras (HART; RISLEY, 1995).

Quanto maior a variedade de livros lidos para uma criança, seja ficção ou não ficção, melhor. A explicação de palavras novas apresentadas no texto, associando-as à sua realidade e 
à nomeação dos objetos que fazem parte do mundo da criança são ações que ajudam muito no desenvolvimento do vocabulário.

\section{2 - MOTIVACÃO AOS MATERIAIS IMPRESSOS (Print Motivatio) - Refere-se} diretamente ao interesse, prazer e reconhecimento, da criança pelos livros. Uma criança motivada a reconhecer livros impressos, gosta que leiam para ela, gosta de brincar com os livros, finge saber escrever e gosta de frequentar as bibliotecas.

$\mathrm{O}$ ato de encorajar a criança a um contato maior com livros, dedicando uma hora especial do dia ou da semana para esta atividade de compartilhá-los e deixá-los acessíveis e permitir à criança perceber que a pessoa que lê para ela tem prazer na leitura, são atos simples e efetivos. A explicação de como a leitura e escrita são usadas no dia a dia também tem impacto muito positivo no desenvolvimento desta habilidade.

\section{3 - NOCÃO/CONSCIÊNCIA DOS MATERIAS IMPRESSOS (Print Awareness) - Esta} habilidade demonstra à criança que tanto a escrita quanto a leitura seguem regras básicas, como ler de cima para baixo e da esquerda para a direita, no caso das línguas ocidentais. Indica o que está impresso naquela página específica do livro e o que está sendo lido. E que isto é feito por uma pessoa que sabe ler. Um bom exemplo de noção de materiais impressos é a habilidade de uma criança de apontar as palavras na página de um livro ou indicar quando um livro ou as palavras nele contidas estão de ponta cabeça.

4 - HABILIDADE NARRATIVA (Narrative Skills) - Ter a capacidade de compreender e contar histórias, descrever as coisas e acontecimentos, são habilidades muito importantes para as crianças entenderem que estão aprendendo a ler. Um exemplo de habilidade narrativa é a capacidade de uma criança contar ou descrever o que aconteceu numa festa de aniversário ou numa visita ao zoológico.

Ao término da leitura do livro, pode-se pedir a criança que repita a história, somente o ato de ouvir pacificamente não ajuda a criança no desenvolvimento da narração. Interrupções por parte das crianças devem ser observadas e permitidas, a leitura deve ser vista como uma experiência positiva. 
5 - CONHECIMENTO DAS LETRAS (Letter Knowledge) - Esta habilidade inclui o aprendizado de que as letras têm nomes distintos e são diferentes umas das outras e possuem sons específicos. A habilidade de uma criança dizer o nome da letra B e o som que esta letra faz quando pronunciada, é um exemplo desta habilidade.

Esta aptidão pode ser desenvolvida usando uma variedade de atividades gostosas e divertidas no dia a dia, como apontar e nomear letras distintas nos livros ou em sinais, letreiros e etiquetas nas ruas, escola, supermercados e em casa.

6 - CONSCIÊNCIA FONOLÓGICA (Phonological Awareness) - Trata-se da habilidade de ouvir e manipular os menores sons nas palavras. É uma habilidade importantíssima no desenvolvimento da criança, pois inclui a capacidade de ouvir e criar rimas, falar palavras enfatizando seus sons ou omitindo sons propositadamente e juntar pedaços de palavras distintas para criar novas palavras. Grande parte das crianças com problemas de leitura apresentam algum tipo de deficiência relativo à noção fonológica.

Para aperfeiçoar ou fortalecer a noção fonológica pode-se brincar com jogos de palavras. Algumas sugestões:

- Criar palavras bobas, trocando o primeiro som numa palavra (como leite, meite, neite, reite, feite);

- Dizer palavras com uma pausa entre as silabas (pas-sa-ri-nho) e deixar a criança tentar adivinhar que palavra está sendo dita;

Pesquisas indicam que quando as crianças entram para o ensino fundamental voltado à alfabetização com as seis habilidades bem desenvolvidas, elas se beneficiam de maneira mais efetiva das instruções de leitura oferecidas pelos professores na alfabetização escolar (REPORT, 2000; NATIONAL RESEARCH COUNCIL, 1998; EAGER, 2001).

Em 2010, no Sistema de Bibliotecas Públicas de Miami, as atividades e programas de Early Literacy foram desenvolvidos nas bibliotecas com o suporte dos pais, das escolas públicas e privadas e de autoridades governamentais como prefeitos e comissários distritais (Commissioners) de cada região. 


\section{Divulgação do Programa de Letramento Infantil pelo MDPLS}

Considerando a faixa etária que o programa de Letramento Infantil tem por públicoalvo e o grande impacto desejado na comunidade, após estabelecimento do Programa dentro do Sistema de Bibliotecas, decidiu-se extrapolar as paredes do Sistema e levar a iniciativa à conhecimento geral. Desta forma, por meio de ações de Outreach (literalmente transpor as paredes da biblioteca e ir até locais de ação), visitas rotineiras são feitas por bibliotecários de cada unidade do Sistema à creches e escolas atendidas pela biblioteca local, para levar ao conhecimento dos educadores, professores e cuidadores de crianças em geral informações sobre o propósito, objetivos e benefícios de atividades de Early Literacy.

São compartilhadas informações e técnicas desenvolvidas e adquiridas no processo de condução do programa. A ideia é que as bibliotecas escolares e centros multimídias compreendam a importância de ações de incentivo o mais cedo possível à leitura, nos usuários com a mais tenra idade, e que com respaldo e assessoria da biblioteca pública desenvolvam atividades de letramento em seus próprios ambientes e bibliotecas escolares voltados ao público de zero meses a cinco anos de idade.

Em relação às creches, são levadas informações e materiais para serem distribuídos para os pais e tutores das crianças, convidando-os à virem à biblioteca participarem do programa junto com os cuidadores e professores, bem como são agendadas visitas, uma vez que geralmente a creche atende crianças de 0 a 3 anos, quando um bibliotecário ou assistente da biblioteca vai até a creche e executa o programa no próprio local.

\section{O atual contexto da Biblioteca Escolar no Brasil}

Em 24 de maio de 2010 foi sancionada pelo Presidente Luiz Inácio Lula da Silva, a Lei ${ }^{\circ} 12.244$ que dispõe sobre a universalização das bibliotecas nas instituições de ensino do país. Ela determina a existência de bibliotecas e bibliotecários em todas as instituições de ensino do Brasil, públicas ou privadas. Dita ainda que seja necessário que a biblioteca possua no mínimo, um livro para cada aluno matriculado.

Para Côrte e Bandeira (2011, p. 8) Biblioteca Escolar "é um espaço de estudo e construção do conhecimento, coopera com a dinâmica da escola, desperta o interesse intelectual, favorece o enriquecimento cultural e incentiva a formação do hábito de leitura". 
Fragoso (2002, p. 4), por sua vez, lista sete funções consideradas ideais de uma biblioteca escolar:
a) cooperar com o currículo da escola no atendimento às necessidades dos alunos, dos professores e dos demais elementos da comunidade escolar;
b) estimular e orientar a comunidade escolar em suas consultas e leituras, favorecendo o desenvolvimento da capacidade de selecionar e avaliar;
c) incentivar os educandos a pensar de forma crítica, reflexiva, analítica e criadora, orientados por equipes inter-relacionadas (educadores + bibliotecários);
d) proporcionar aos leitores materiais diversos e serviços bibliotecários adequados ao seu aperfeiçoamento e desenvolvimento individual e coletivo;
e) promover a interação educador-bibliotecário-aluno, facilitando o processo ensino- aprendizagem;
f) oferecer um mecanismo para a democratização da educação, permitindo o acesso de um maior número de crianças e jovens a materiais educativos e, através disso, dar oportunidade ao desenvolvimento de cada aluno a partir de suas atitudes individuais; g) contribuir para que o educador amplie sua percepção dos problemas educacionais, oferecendo-lhe informações que o ajudem a tomar decisões no sentido de solucioná- los, tendo como ponto de partida valores éticos e cidadãos.

Podemos considerar que no paradigma atual do conhecimento, as ações da biblioteca devem ser projetadas no sentido de garantir o desenvolvimento e construção de competências para conduzir seus usuários em processos de aprendizagens contínuas e dar-lhes condições de "aprender a aprender".

Tomando por referencia o item c) apresentado por Fragoso, chama-nos a atenção os verbos incentivar e pensar seguidos dos adjetivos crítico e analítico, referindo-se ao sujeito alunos. Reforça ainda a autora, no mesmo item, a questão da interdisciplinaridade de atores, neste caso professores e bibliotecários, para incentivar tais práticas de maneira mais efetiva.

Ainda, O Manifesto da IFLA/UNESCO para bibliotecas escolares, datado de 2006, estabelece a biblioteca escolar como responsável pelo desenvolvimento e promoção do prazer da leitura, sendo que seus usuários tenham as tecnologias incorporadas de forma natural e imediata nas suas rotinas sociais, comunicativas, informacionais, educacionais e de lazer.

Remetendo a Freire (1988, p. 11) "a leitura de mundo precede a leitura da palavra". O ato de ler configura-se também em um dos muitos mecanismos para a compreensão da realidade ao propiciar ao indivíduo uma percepção mais global e mais crítica das situações e do contexto social no qual se encontra inserido. Atualmente, almejamos leitores não apenas alfabetizados, mas leitores que saibam ler e tenham condições de fazê-lo de forma reflexiva, analítica, compreensiva e com capacidade para tomar decisão quanto ao uso de suas habilidades de escrita e leitura, em prol de uma sociedade mais ética e justa. 
O Brasil precisa construir 130 mil bibliotecas até 2020 para cumprir a Lei 12.244, que estabelece a existência de um acervo de pelo menos um livro por aluno em cada instituição de ensino do País, tanto de redes públicas como privadas. Hoje, na rede pública, apenas 27,5\% das escolas têm biblioteca (BALMAT, 2013).

Ainda, por conta da lei, observa-se grande oferta de cursos de graduação, especialização, técnicos nas áreas de Biblioteconomia e Ciência da Informação por parte de escolas técnicas, faculdades e universidades. É grande também a procura dos estudantes, futuros bibliotecários, técnicos e auxiliares de bibliotecas, gestores de bibliotecas escolares interessados em atender a esta importante demanda do mercado.

Estamos vivendo um momento peculiar, somente a legislação não é suficiente. Além da preocupação com o estabelecimento da própria infraestrutura para abrigar a biblioteca escolar, seus recursos, produtos e serviços informacionais direcionados aos seus usuários, existe ainda a preocupação com a formação e adequada qualificação de profissionais para atuar de maneira adequada e inteligente.

\section{Primeira infância, educação infantil, letramento e alfabetização no Brasil}

No Brasil, atribui-se o termo primeira infância à faixa etária de zero a seis anos de idade. De um modo geral, chama-se Primeira Infância ao período que vai desde a concepção do bebê até o momento em que a criança ingressa na educação formal (KUHLMANN JR., 2000)

A Primeira Infância é um período muito importante para o desenvolvimento da criança e as experiências dessa época são relevantes para o resto da vida, mesmo aquelas que acontecem durante a gestação. Durante a Primeira Infância ocorre o crescimento físico, o amadurecimento do cérebro, a aquisição dos movimentos, o desenvolvimento da capacidade de aprendizado, a iniciação social e afetiva. Os estudos mostram que quanto melhores forem as condições para o desenvolvimento durante a Primeira Infância, maiores são as probabilidades de que a criança alcance o melhor do seu potencial tornando-se um adulto mais equilibrado, produtivo e realizado.

Como explica Becker (2008), a educação infantil no Brasil caracteriza-se como a etapa inicial da educação, reconhecida como direito da criança em inúmeros documentos. Ela visa 
atender a criança de zero a seis anos, dividindo-se em duas etapas: a creche (zero a três anos) e a pré-escola (quatro a seis anos)

Alfabetização é "a ação de alfabetizar, tornar o indivíduo capaz de ler e escrever" Com o aparecimento do termo literacy surge letramento, como ação de ensinar e aprender práticas sociais de leitura e escrita. Nesse sentido,

Ter-se apropriado da escrita é diferente de ter aprendido a ler e escrever: aprender a ler e escrever significa adquirir uma tecnologia, a de codificar em língua escrita e de decodificar a língua escrita; apropriar-se da escrita é tornar a escrita "própria", ou seja, é assumi-la como sua propriedade" (SOARES, 2004).

Entretanto, há uma preocupação com relação à qualidade da leitura e da escrita, pois frequentemente há confusão entre o saber ler e escrever, para o ser capaz de fazer uso do ler e escrever. Dessa forma, tornou-se importante o estudo mais detalhado da diferença entre a alfabetização e o letramento. “Alfabetização é a ação de ensinar/aprender a ler e a escrever; e letramento é o estado ou condição de quem não apenas sabe ler e escrever, mas cultiva e exerce as práticas sociais que usam a escrita” (SILVA; LIRA, 2003, p. 24).

Soares (2004) defende sua posição quanto à alfabetização ser concomitantemente com o letramento. Ela acredita que no Brasil a escola deve alfabetizar e letrar os alunos ao mesmo tempo, sendo importante a introdução da prática social da leitura e da escrita já desde os primeiros anos escolares.

Corroborando com Soares, Monteiro (2010, p. 33) atesta sobre a questão do letramento “[...] pode-se perceber que práticas de letramento, devem acontecer juntamente com atividades de alfabetização, já na educação infantil, uma vez que estes conceitos se complementam, para oferecermos um espaço de acesso à leitura e escrita completo”.

Assim, é importante o desenvolvimento de atividades que possam dinamizar o desenvolvimento cognitivo da criança com atividades e práticas que subsidiem e incentivem tanto seu letramento quanto alfabetização. 


\section{Letramento Infantil na Biblioteca Escolar - Aprender brincando}

Mesmo na convivência com meios eletrônicos de armazenamento e acesso à informação, o conhecimento que circula na sociedade ainda tem no livro o seu principal meio e nas bibliotecas o local para a guarda do acervo e da memória de um povo. Segundo Eco, "as bibliotecas, ao longo dos séculos, têm sido o meio mais importante de conservar nosso saber coletivo. Foram e ainda são uma espécie de cérebro universal onde podemos reaver o que esquecemos e o que ainda não sabemos" (ECO, 2003).

Retomando a história da literatura infantojuvenil fica evidente que somente a partir do século XVIII a criança passa a ser considerada um ser diferente do adulto, com necessidades e características próprias, pelo que deveria distanciar- se da vida dos mais velhos e receber uma educação especial, que a preparasse para a vida adulta.

Em meados do século XX surgem novas concepções sobre o público infanto-juvenil e seu processo de aprendizado, principalmente com a disseminação dos mais recentes estudos sobre a psicolinguística, que giram em volta do lúdico e da sociabilização da criança.

É ouvindo histórias que se pode sentir emoções importantes, como a tristeza, a raiva, a irritação, o bem estar, o medo, a alegria, o pavor, a insegurança, a, e tantas outras

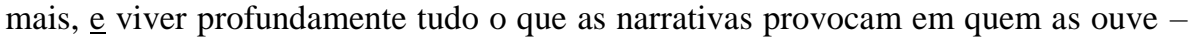
com toda a amplitude, significância e verdade que cada uma delas fez (ou não) brotar... Pois é ouvir, sentir e enxergar com os olhos do imaginário! (ABRAMOVICH, 1989, p. 17.?)

Ainda, ilustrando o relevante papel da biblioteca escolar como extensão da sala de aula para os pequenos usuários, referimos a Silva (1997, p. 11),

A força da historia é tamanha que o narrador e ouvintes caminham juntos na trilha do enredo e ocorre uma vibração recíproca de sensibilidades, a ponto de diluir-se o ambiente diante da magia da palavra que comove e enleva. A ação se desenvolve e nós participamos dela, ficando magicamente envolvidos com os personagens, mas sem perder o senso critico que é estimulado pelos enredos.

Uma biblioteca escolar na qualidade de espaço pedagógico tem por meta ser um local de ensino e aprendizagem, que pode transcender suas funções básicas e criar alternativas e parcerias para enriquecer suas formas de ação na comunidade.

Hommerding (2011, p. 47) apresenta três dimensões nas quais se apoiam evidências da importância dos estímulos dados aos bebês e crianças até a fase da pré-escola (zero a seis anos de idade), fase criticamente importante para o desenvolvimento e estímulo de habilidades do letramento infantil. 
Letramento Infantil na Biblioteca Escolar: desenvolvendo habilidades básicas para futuros leitores competentes

Quadro I - Estímulo ao Desenvolvimento Infantil

\begin{tabular}{|c||l||}
\hline \multicolumn{1}{|c||}{ Áreas } & \multicolumn{1}{|c|}{ Características } \\
\hline \hline Biologia (Neurociência) & $\begin{array}{l}\text { Pesquisas revelam que bebês nascem com cerca de 100 } \\
\text { bilhões de células desconectadas e que por meio de } \\
\text { interações sensoriais (ver, ouvir, cheirar, provar e tocar) } \\
\text { estas células neurais se conectam, formando as sinapses } \\
\text { ou conexões. }\end{array}$ \\
\hline \hline Aspectos ambientais & $\begin{array}{l}\text { Necessidade da criação de um ambiente propício e } \\
\text { convidativo para o aprendizado. O letramento infantil } \\
\text { começa no nascimento e acontece em casa, na creche, na } \\
\text { escola, na biblioteca. O ambiente e seus recursos devem } \\
\text { ser adequados para trabalhar e estimular corretamente } \\
\text { Habilidades do Letramento } \\
\text { Infantil }\end{array}$ \\
\hline \hline Desenvolvimento das Seis & $\begin{array}{l}\text { Processo ativo que ocorre quando a criança está } \\
\text { engajada na conversação. Ambientes ricos em } \\
\text { linguagem e vocabulário, como por exemplo, as } \\
\text { bibliotecas são cruciais para aquisição dessas } \\
\text { habilidades. }\end{array}$ \\
\hline \hline
\end{tabular}

Fonte: Hommerding (2011, p. 47-48)

Pensando no papel da biblioteca escolar na formação de leitores, ou no caso específico do público-alvo deste artigo, pré-leitores, podemos presumir um espaço cuja dinâmica esteja voltada para atividades lúdicas de aprendizado. Uma biblioteca escolar inserida em uma sociedade informacional como lugar fundamental para o processo de ensino e aprendizagem, um espaço dinâmico de troca de saberes. Concebida como uma instituição transmissora de informação e da troca de conhecimentos, a biblioteca escolar torna-se um centro de investigação e aprendizagem indispensável para o ensino.

As crianças começam a adquirir habilidades de letramento infantil já quando nascem em atividades rotineiras como compartilhando livros, contando histórias, cantando canções, conversando uns com os outros ou apontando e dando nomes às coisas e objetos (BOHRER; 2005; GHOTING, 2006; DOHER-COHEN, 2007). Estas atividades ajudam na expansão e enriquecimento de seus vocabulários, além de estimular o desenvolvimento do cérebro. 
Engajar as crianças na atividade de leitura e no que está sendo lido, ajuda a promover seu pensamento crítico e imaginativo. Também melhora seu desenvolvimento intelectual e emocional, ajudando-as a adquirirem habilidades de pré-leitura necessárias para agilizar seu sucesso no aprendizado estruturado de leitura e escrita durante sua vida escolar e social.

Para que este engajamento ocorra, além do próprio livro, que também é um brinquedo, deve-se usar diversos outros tipos de recursos como as brincadeiras de roda, canções, blocos de construção, brinquedos educativos, instrumentos musicais, jogos, quebra-cabeças, animais de pelúcia, recursos audiovisuais etc.

\section{A importância do alinhamento entre as estratégias e planos pedagógicos da Escola e da Biblioteca Escolar}

Para a biblioteca escolar cumprir sua importante missão e os objetivos pedagógicos da instituição de ensino serem atingidos com maior plenitude, é imprescindível que tanto a missão quanto os objetivos da biblioteca estejam alinhados e sejam parte integrante do projeto político-pedagógico da escola.

Isto significa um diálogo aberto entre bibliotecários, diretores, professores, pedagogos, coordenadores, enfim todo o corpo profissional do fazer e ensinar educacional.

O planejamento e plano de ação pedagógico e metodológico deve trazer contribuições de todas as áreas do conhecimento envolvidas. Vale lembrar, bibliotecários lidam com informação, conhecimento e pessoas que buscam e necessitam de informações e letramento, não com o objeto livro. O livro é o meio, ou melhor, na sociedade contemporânea, um dos meios, não o fim de uma biblioteca.

A Lei 12.244/10 destaca sobre a biblioteca escolar, no segundo artigo, [...] "Considerase biblioteca escolar a coleção de livros, materiais videográficos e documentos registrados em qualquer suporte destinado a consulta, pesquisa, estudo ou leitura". A lei deixa evidente que não é apenas o livro que as bibliotecas devem possuir no seu acervo, mas diversos materiais de leitura em vários suportes, pois a leitura pode ser praticada de diversas maneiras e necessita de diferentes materiais e por isso a Política de Desenvolvimento de Coleções das bibliotecas escolares devem abordar critérios de seleção envolvendo variado acervo de suportes de materiais de informação, além da participação efetiva dos professores e 
coordenadores na definição dos tipos de materiais didáticos e paradidáticos a serem usados, para o melhor desenvolvimento e aperfeiçoamento pedagógico dos alunos. (BRASIL, 2010)

Para desenvolver hábitos de leitura no público infantil é fundamental a realização de projetos de leitura tanto pelos por professores como por bibliotecários. Esses projetos podem incluir diversas atividades que podem ser realizadas dentro do recinto da biblioteca escolar, pois as bibliotecas são espaços por sua natureza privilegiados destinados a leitura, ou a biblioteca deve ir até a sala de aula e levar também contribuições e oportunidades impares, por meio de seus produtos e serviços, aos educandos e professores.

\section{Considerações finais}

Para bebes e crianças até a idade pré-escolar (zero mês a seis anos), o contato e interação com livros, brinquedos, jogos, brincadeiras, bibliotecas, de maneira dirigida, porém lúdica e divertida traz benefícios incontestáveis para o desenvolvimento mais efetivo de habilidades de leitura e escrita.

Assim, todas as oportunidades para ler, cantar, ouvir e contar histórias, montar quebracabeças, pintar etc. são impactantes para o seu futuro. A partir dos seis meses, e mesmo antes, as crianças começam a interessar-se por figuras e imagens e a associá-las à sons. É por isso que, a partir de então, elas devem ter contato com os primeiros livros (feitos de materiais seguros, como cartão grosso, pano ou de plástico) contendo figuras simples, coloridas e facilmente identificáveis.

No que se refere ao conteúdo, isso diversifica e expande a linguagem utilizada com a criança, amplia a realidade, estimula a imaginação, a associação de ideias, a capacidade de concentração, ajuda a lidar com emoções e medos, transmite regras e sistemas de valores. $\mathrm{O}$ livro é também uma ponte emocional entre as crianças e os adultos, ajudando-os a interagir e a estarem juntos, criando um ambiente de segurança e confiança.

A idade com que a criança se inicia na leitura é um fator que favorece o desenvolvimento da linguagem e do interesse e prazer por essa atividade ao longo da vida. A estimulação por meio dos livros, o quanto antes possível, e a interação com os adultos no ambiente familiar e na biblioteca está associada ao maior desenvolvimento da linguagem, 
interesse pela leitura e ao desenvolvimento de aptidões essenciais para o aprendizado constante da criança e seu futuro desenvolvimento.

As bibliotecas escolares representam a ponte essencial entre a família, o aluno, a escola e o aprendizado. Gestores e profissionais atuantes nessa área têm a oportunidade de desenvolver um significativo trabalho por meio do letramento infantil, essencial e com resultados positivamente impactantes na vida escolar de uma criança, a médio e longo prazo. Ao menos, nos Estados Unidos e Canadá, relatórios e resultados já estão sendo feitos e mostrados em estudos e estatísticas governamentais.

Ao falar de biblioteca escolar pode-se pensar, por tradição, no espaço voltado às crianças que adentram o ensino fundamental, entretanto, e aquelas crianças de 3 a 6 anos de idade? Quais as ações em relação a este público real? E, talvez a pergunta mais importante ainda fosse: Que serviços e produtos oferecer?

No Brasil, as bebetecas vêm surgindo dentro da realidade das creches, o que as torna uma espécie de biblioteca escolar. Mas, e o papel das bibliotecas escolares neste cenário? A presença passiva das bibliotecas escolares necessita ser questionada.

Uma biblioteca escolar deve fornecer à criança um ambiente que conduza ao seu bemestar e aos processos de aprendizagem ao seu redor. É este o pano de fundo para a proposta de promover uma biblioteca escolar funcional. Esta é também uma oportunidade da biblioteca escolar assumir o papel que nem sempre as bibliotecas públicas conseguem atingir, pois muitas crianças chegam à escola sem jamais terem visitado ou usado uma biblioteca pública.

Pré-escolas e escolas do ensino fundamental podem estabelecer um Serviço de Empréstimo Familiar, possibilitando, aos pais e cuidadores, livros que auxiliem no processo de aprendizado, letramento e desenvolvimento infantil, bem como livros que possam ler aos seus filhos. Tal coleção deve ainda conter, além dos próprios livros, DVDs, vídeos, CDs e uma variedade de materiais que atendam a especificidade de cada família.

Além do desenvolvimento das competências, um dos principais objetivos, e talvez o mais importante, de um programa de Letramento Infantil reflete-se no fortalecimento dos laços afetivos entre o adulto e a criança, sejam pais, cuidadores, professores, tutores, avós, babás, tios etc. Uma oportunidade preciosa de compartilhar amor, carinho, atenção, respeito e admiração mútua, além de informação e conhecimento, por meio da leitura e atividades lúdicas. 
O Letramento Infantil é uma responsabilidade social e profissional cuja participação técnica e intelectual do bibliotecário, professores, coordenadores, enfim, todo o corpo inter e multidisciplinar da escola tem papel inquestionável. Trata-se de um desafio e primordial oportunidade de ação.

\section{Referências}

ABRAMOVICH, F. Literatura infantil: gostosuras e bobices. 2. ed. São Paulo: Scipione, 1989.

BALMAT, O. Em 72,5\% das escolas brasileiras não há biblioteca. Estadão, São Paulo, Geral, 23 jan. 2013. Disponível em: <http://www.estadao.com.br/noticias/geral,em-72-5-dasescolas-nao-ha-biblioteca-lei-preve-obrigatoriedade-ate-2020-imp-,987556>. Acesso em: maio 2014.

BECKER, F. R. Educação infantil no Brasil: a perspectiva do acesso e do financiamento. Revista Ibero americana de Educación, n. 2, 2008. Disponível em:

<http://www.rieoei.org/rie47a07.htm>. Acesso em: 15 ago. 2012.

BOHRER, C. N. Libraries as early literacy centers. Public Libraries, v. 44, n. 3, 2005. 132p.

BRASIL. Senado Federal. Lei 12244 de 24 de maio de 2010. Disponível em: $<$ http://presrepublica.jusbrasil.com.br/legislacao/823116/lei-da-biblioteca-escolar-lei-1224410>. Acesso em: 03 jul. 2013.

CÔRTE, A. R.; BANDEIRA, S. P. Biblioteca escolar. Brasília: Briquet de Lemos, 2011.

DOHER-COHEN, B.; RIORDAN, E.; WADE, R. Make way for dendrites: how brain research can impact children's programming. Children and Libraries. 2004. v. 2, n. 12, 20 p.

DUKE, N.; MOSES, A. 10 Research tested ways to build children's vocabulary. Scholastic, 2003.

EAGER to learn: educating our preschoolers. Washington: National Academy Press, 2001. Disponível em: 〈http://www.nap.edu/>. Acesso em: 15 ago. 2010.

ECO, U. Muito além da Internet. Infohome. 2003. Disponível em: <http://www.ofaj.com.br/textos_conteudo.php?cod=16>. Acesso em: 07 ago. 2010.

FRAGOSO, G. M. Biblioteca na escola. Revista ACB: Biblioteconomia em Santa Catarina, Florianópolis, v. 7, n. 1, 2002.

FREIRE, P. A importância do ato de ler: em três artigos que se completam. 22 ed. São Paulo: Cortez, 1988. Disponível em: <http://www.fmcsv.org.br/pt-br/Paginas/primeirainfancia.aspx $>$. Acesso em: 22 ago. 2014. 
GOTHING, S.; MARTIN-DIAZ, P. Early literacy storytimes @ your library: partnering with caregivers for success. ALA Editions, 2008. 272 p.

HART, B.; RISLEY, T. Meaningful differences in the everyday experience of young American children. Baltimore: Paul Brookes, 1995.

HOMMERDING, N. M. S. O papel da Biblioteca Pública no letramento infantil (early literacy): o modelo norte-americano e a oportunidade brasileira. In: VALLS, V. M;

VERGUEIRO, W. Tendências contemporâneas na gestão da informação. São Paulo: Ed. Sociologia e Política, 2011. 151 p.

IFLA/UNESCO. As directrizes da IFLA/UNESCO para Bibliotecas escolares. 2006. Disponível em: http://www.ifla.org/files/assets/school-libraries-resourcecenters/publications/school-library-guidelines/school-library-guidelines-pt.pdf $>$. Acesso em: 15 jun. 2013.

KISHIMOTO, T. M. Alfabetização e letramento/literacia no contexto da educação infantil: desafios para o ensino, para a pesquisa e para a formação. Revista Múltiplas Leituras, v. 3, n. 1, p. 18-36, jan. jun. 2010. Disponível em:

<https://www.metodista.br/revistas/revistasims/index.php/ML/article/viewFile/1902/190>. Acesso em: 02 set. 2010.

KUHLMANN JR., M. Histórias da educação infantil brasileira. Revista Brasileira de Educação, n. 14, maio/ago. 2000. Disponível em:

<http://www.scielo.br/pdf/rbedu/n14/n14a02 >. Acesso em: 14 jul. 2014.

MEYERS, E., HENDERSON, H. Overview of every child ready to read @ your library, 2004. Disponível em:

<http://www.ala.org/ala/mgrps/divs/alsc/ecrr/projecthistory/ecrroverview/ecrroverview.cfm $>$. Acesso em: 10 ago. 2013.

MONTEIRO, D. R. S. Alfabetização e letramento na educação infantil: oferecendo um espaço de acesso à leitura e escrita antes do ensino fundamental. Posto Alegre: Universidade Federal do Rio Grande do Sul, 2010. 35 p. Disponível em:

<http://www.lume.ufrgs.br/bitstream/handle/10183/36525/000818231.pdf >. Acesso em: 19 set. 2012.

NATIONAL RESEARCH COUNCIL. Preventing reading difficulties in young children. Washington: National Academy Press, 1998. Disponível em: 〈http://www.nap.edu〉. Acesso em: 02 set. 2011.

PAYNE, A,; WHITEHURST, G.; ANGELL, A. The role of home literacy environment in the development of the language ability in preschool children for low-income families.

Early Childhood Research Quarterly, v. 9, n. 3-4, p. 422-44, 1994.

READING ready: early literacy resource manual. Miami Dade Public Library System, Nov. 2009. 
REPORT of the National Reading Panel: teaching children to read, an evidence-based assessment of the scientific research. Literature on Reading and Its Implications for Reading Instruction. NICHD, 2000.

SILVA, M. B. C. Contar histórias uma arte sem idade. 7. ed. São Paulo: Ática, 1997.

SILVA, A. L.; LIRA, V. K. Letramento na educação infantil. Rio de Janeiro: E-paper, 2003.

SOARES, M. Letramento e alfabetização: as muitas facetas. Revista Brasileira de Educação, Campinas, n. 25, jan./abr., 2004. Disponível em:

<http://www.scielo.br/pdf/rbedu/n25/n25a01.pdf $>$. Acesso em: 18 mar. 2015.

Letramento: um tema em três gêneros. Belo Horizonte: Autêntica, 2001.

WHITEHURST, G. J.; LONIGAN, C. J. Emergent literacy: development from prereaders to readers. In: NEUMAN, S. B.; DICKENSEN (Ed.) Handbook of Early Literacy Research. New York: Guilford, 2001. p. 11-29.

Artigo enviado em: 24 fev. 2016

Artigo aceito em: 30 mar. 2016 